\title{
Sustaining Graduation: A Review of the CLM Programme in Haiti
}

\author{
Chris Pain, Emilie Vautravers and Alain Descieux
}

\begin{abstract}
The Haitian NGO Fonkoze, with the support of Concern Worldwide, has been implementing the Chemin Lavi Miyo (CLM) Graduation Programme since June 2007 which targets the extreme poor in Haiti. Early results were promising, but questions prevailed around the sustainability of benefits. To address these concerns a further round of data collection was undertaken amongst a group of participants four years after graduation. Using a poverty scorecard to record information on housing quality, ownership of assets, household income and livelihoods, it was possible to assess that the mean level of asset-holding remained higher than at baseline, but had slipped back slightly since graduation. Between graduation and the ex post survey 31 per cent continued on an upward trajectory, 39 per cent consolidated their position, but 30 per cent had slipped back considerably, suggesting the need for a more comprehensive social protection system than can be offered by an NGO-implemented programme.
\end{abstract}

\section{Introduction}

The image of a predatory state, which extracts but does not invest or redistribute is a constant in the social analyses of Haiti, but a recent review of initiatives undertaken by the Haitian government shows that the reality is quite different from the 'antithesis of the welfare State' (Lamaute-Brisson 2013) frequently presented. Since Haiti signed up to the provision of a Social Protection Floor in 2010, it has adopted a myriad of interventions, often on a pilot basis. Under the non-contributory pillar this incorporates school canteens, free obstetric care, free schooling such as the $\mathrm{Ti}$ Manman Cheri Programme focused on the retention of children in primary school from the most disadvantaged areas, monetary transfers and support to poor families. ${ }^{1}$ There are also longer standing but weak public social security organisations covering insurance and social assistance. Concurrently, there are programmes against hunger and malnutrition under the umbrella of $A b a$ Grangou ('down with hunger!'), created in 2012 to bring about some programmatic coherence in the area, covering school feeding programmes, cash transfers and food distribution for mothers and vulnerable people and a multipurpose community agent initiative. The challenge may well be that these are $a d h o c$ in nature and uncoordinated with other actors, leading to a 'balkanisation' of initiatives (ibid.) and with non-governmental organisations (NGOs) being left to fill many of the gaps left by state inactivity.

Against this background Fonkoze, Haiti's leading microfinance institution, with support from Concern Worldwide, have been implementing the Chemin Lavi Miyo (CLM), or 'the pathway to a better life' project, designed as an intervention to tackle extreme poverty at an individual level in Haiti. CLM is a multi-pronged livelihood protection and promotion scheme, belonging to the graduation family, as first developed by the Bangladesh Rural Advancement Committee (BRAC) in Bangladesh. ${ }^{2}$ The project was piloted over an 18-month period between June 2007 and December 2008, in three locations in Haiti Boucan Carre, Pointe-à-Raquette on the island of La Gonave and Trou-du-Nord. In this pilot phase, 150 female heads of household were enrolled in the pilot, 50 from each location. The programme was built around five core elements:

a The comprehensive targeting of the poorest women in the community;

b Support in the form of a cash transfer specifically to assist with basic needs, food security and health care for a six-month period; 
c Establishing formal savings into which participants are encouraged to put a small amount of money on a weekly basis;

d Skills training and regular coaching (accompaniment) for a period of 18 months;

e The transfer of two productive assets to assist with kick-starting a sustainable economic activity - usually a choice between livestock (goats or chickens) or the local equivalent of US $\$ 40$ to start a trading business.

While the CLM programme follows an assetbased 'staircase out of poverty', the programme also stresses the 'handrails' in the form of education and health services. ${ }^{3}$ Other elements have been included based on an assessment of needs including enhancing access to education, water filtration, housing repairs, the construction of latrines, and the provision of health advice. The programme attempts to address issues of social inclusion and enhancing the self-confidence of programme participants through caseworker visits and their better integration in the social life of the community. Social links have been developed with village elites through the Village Assistance Committees comprising influential people in the local area, alongside members of mainstream microfinance programmes and a CLM participant (Huda and Simanowitz 2009). Elements of behaviour change in particular are a key part of the visits by the case manager who develops quarterly goals with the participants.

The overall purpose of CLM was to strengthen the productive assets and asset management of the extreme poor so that they can graduate into one of two paths which will assure continuing and sustained progress out of poverty. For Fonkoze this includes being able to access a larger credit programme known as Ti Kredi, the next step up from CLM in Fonkoze's tiered strategy, or to use their savings and existing assets to grow and diversify their capital base. In this respect, the CLM programme takes an 'endogenous' approach towards graduation (Samson 2014), with families assessed for their readiness for graduation, and participants being unable to graduate out of the programme if they had a malnourished child, were too sick to work, or had a shoddy roof. ${ }^{4}$ The initial success of the programme, as identified in a number of evaluations, ${ }^{5}$ led to its expansion and by the end of September 2013 Fonkoze had graduated 2,364
CLM members (including almost 1,000 with the support of Concern), with a further 1,261 currently going through the programme.

In the final quarter of 2012 Concern and Fonkoze felt the time was right to revisit a sample of the beneficiaries included in the pilot phase of the exercise to see how sustainable the benefits acquired by graduation had proven to be. The following presents some of the key findings of this exercise.

\section{Methodology}

The results in the following are based primarily on quantitative data collection carried out over a number of rounds. This compares 82 beneficiaries ${ }^{6}$ across the three locations at three points of time using a number of indicators drawn from a poverty scorecard (known as the Kat Evalyasyon). The Kat Evalyasyon is based on the Progress out of Poverty Index which identifies a number of questions about a household's characteristics and asset ownership that are scored to compute the likelihood that the household is living below the poverty line (Grameen Foundation 2014), making it a proxy means test.

Over the various rounds of data collection the questions included in the Kat Evalyasyon have remained reasonably consistent, addressing the programme participant's housing, their ownership of specific goods, household income and more general information. Information on the participant's house was collected using seven specific questions covering the construction materials of the house, the roof and the floor, whether the household owned the house and the land on which it stands, the number of rooms in the house and the type of toilet. A series of six questions was included on the scorecard to measure information on goods available in the household, specifically dealing with the type of bed the participant slept on, whether she had electricity, whether she owned a bundle of specific household assets, how much land she had, what she did with the land and whether she had livestock. The third section dealt loosely with sources of household income, including the receipt of money transfers from abroad. The fourth component recorded whether the participant can read and write, how many children she has, how many children go to school, how many times per week they cook meat in the 
house and how many people live in the house. However, in the analysis, not all questions were included as some would not reasonably expect to have changed over time and some were not asked in precisely the same way. Once these were removed, 16 components were left for inclusion, dealing with the quality of housing, ownership of key assets, children's attendance at school and consumption level indicators, such as whether the household had cooked meat in the past week. A score was attributed to each, creating a scale that could record a maximum of 42.5 and a minimum of zero.

The data from the scorecard was collected first in June 2007 (baseline), two years later in June 2009 (12 months after the end of the cash stipend) and in October 2012 (almost four years after graduation); unfortunately, no counterfactual is available for this group of beneficiaries, so it is not possible to attribute definitively the improvements to the CLM intervention. Notwithstanding, global food price increases (2008), a succession of hurricanes (2008 and 2012) and a devastating earthquake (2010) have all ravaged Haiti in this period. Between 2007 and 2011, gross national income per capita remained virtually unchanged, increasing from US $\$ 1,150$ in 2007 to US $\$ 1,180$ in 2011, dipping as low as US $\$ 1,120$ in $2010^{7}$ so it is reasonable to assess that any progress recorded can largely be attributed to the CLM programme.

\section{Results}

\subsection{Changes in housing (2007 to 2012)}

In 2007 (at the baseline) the majority of programme participants' houses were made from turf or earth (80.5 per cent), the most common roofing material was straw (59.8 per cent), with the remainder utilising iron, and almost all participants lived in houses with an earth floor (97.6 per cent). Most respondents lived in tworoom houses (57.3 per cent) and virtually all (97.6 per cent) reported having no toilet, while 73.2 per cent said they owned their own house and 43.9 per cent said they owned the land on which their house stood.

By the time of the 2012 survey the most frequently cited construction material was cement/blocks with wood/stone, given by 42.7 per cent of respondents, with 91.5 per cent having iron roofs. While the majority of participants still lived in houses with earth floors, the proportion had decreased to 74.4 per cent, with 19.5 per cent living in houses with a cement floor. Even though there was little change in terms of the average number of rooms in the house, with 56.1 per cent living in houses of two rooms, there was a large increase in the proportion of respondents saying they had latrines made from cement (42.7 per cent). The majority of those surveyed in 2012 (86.6 per cent) said they owned their own house, and the land on which their house stood (62.2 per cent).

Out of a maximum possible score of 18.5 points for the quality of housing, the mean score at baseline was 3.7, increasing to 7.2 at graduation and continuing to increase to 7.8 in 2012 .

Looking at an individual basis, between baseline and graduation 96.2 per cent (the equivalent of 79 beneficiaries) had a higher score; however, four years later slightly more than a third of beneficiaries had slipped back in terms of their quality of housing, with 57.7 per cent further improving their score. This translates into a small number of respondents (five) living in housing that was of poorer quality in 2012 than at the programme start in 2007.

\subsection{Changes in access to goods (2007 to 2012)}

At baseline, the largest proportion of respondents (39 per cent) slept on something on the ground, followed by an iron bed (36.6 per cent), nobody had electricity, and very few respondents owned even a small radio or flashlight. In terms of quantity of land, the most common response was that they had a small plot or less (86.6 per cent), and that they did nothing with this (69.5 per cent of respondents); over half (58.5 per cent) said they had no livestock. In the 2012 survey the most frequent response was that participants slept on an iron (48.8 per cent) or wooden (28 per cent) bed, a large majority still did not have access to electricity, and a low 4.9 per cent of respondents owned a black-and-white television or radio cassette player. The proportion who said they did nothing with their land had dropped (to 56.1 per cent), as had the percentage saying they had no livestock (30.9 per cent), representing improvements over the baseline figures.

Again, when combining these responses into a single score, change can be seen between baseline, when the mean score amongst beneficiaries was 2.3 out of a possible 16, and the 2012 survey, when the mean score reached 4.1; 


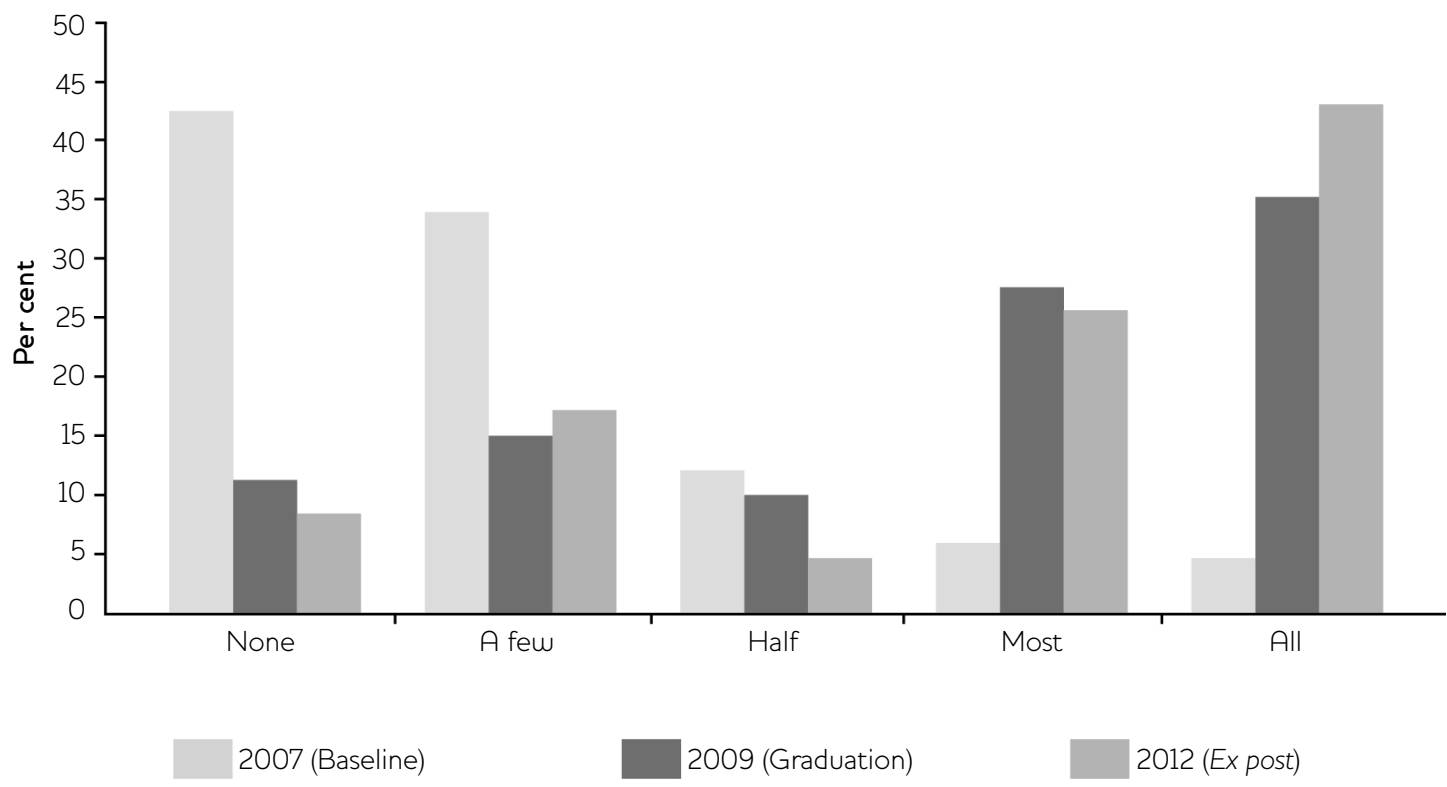

Source Authors' own calculations based on existing data sets.

however, this represents a considerable decline in the score for goods from the immediate postgraduation period, when the combined score was 5.9. This translates to slightly more than twothirds of respondents (53, or 67.9 per cent) recording a decline between graduation and 2012, with 12 (15.4 per cent) managing to maintain their 2009 level and 13 (16.7 per cent) improving their goods score from graduation. However, follow-up work undertaken by Fonkoze in Boucan Carre in 2013 found sizable differences between beneficiaries and people who were of a similar economic status but who had not been included in the programme almost two out of three of the counterfactual group had no animals, while only 4.4 per cent of beneficiaries said this was the case.

\subsection{Changes in household income}

The third section deals with questions related to household income, but rather than trying to assess how much this income is, the focus was more on sources of additional income. ${ }^{8}$ Participants were asked if they had a spouse or partner and if they did what kind of work he did and what proportion of his income he contributed to the household. The final question related to whether the participant received money transfers from abroad. The mean score at baseline on this index was 2.1 out of 10 , increasing to 2.8 by 2012 , a decline from the immediate post-graduation score of 3.3, but still one-third above the baseline value.

At baseline, 67.1 per cent of participants had a spouse or partner; for those who stated the type of work that he did, the most common response was that he was a day labourer or tenant farmer. Responses to the proportion of income contributed to the household were varied, and virtually nobody (92.7 per cent) received a transfer from abroad. In the 2012 survey, the proportion of participants with partners had dropped slightly to 63 per cent, though the range of activities they were engaged in had changed, with a much greater proportion (39.5 per cent) now being engaged in farming or petty commerce. The proportion of income they contributed to the household improved with 40.7 per cent giving most or all. Again, only a small proportion of participants were receiving transfers from abroad. This corresponds to 22 (27.2 per cent) respondents having a score for income that was worse in 2012 than 2007, with 15 (18.5 per cent) having no change and 44 (54.3 per cent) having an improvement.

\subsection{Basic changes in the participant's status}

The fourth component of the poverty scorecard contains information on five specific indicators whether the participant can read and write, how 


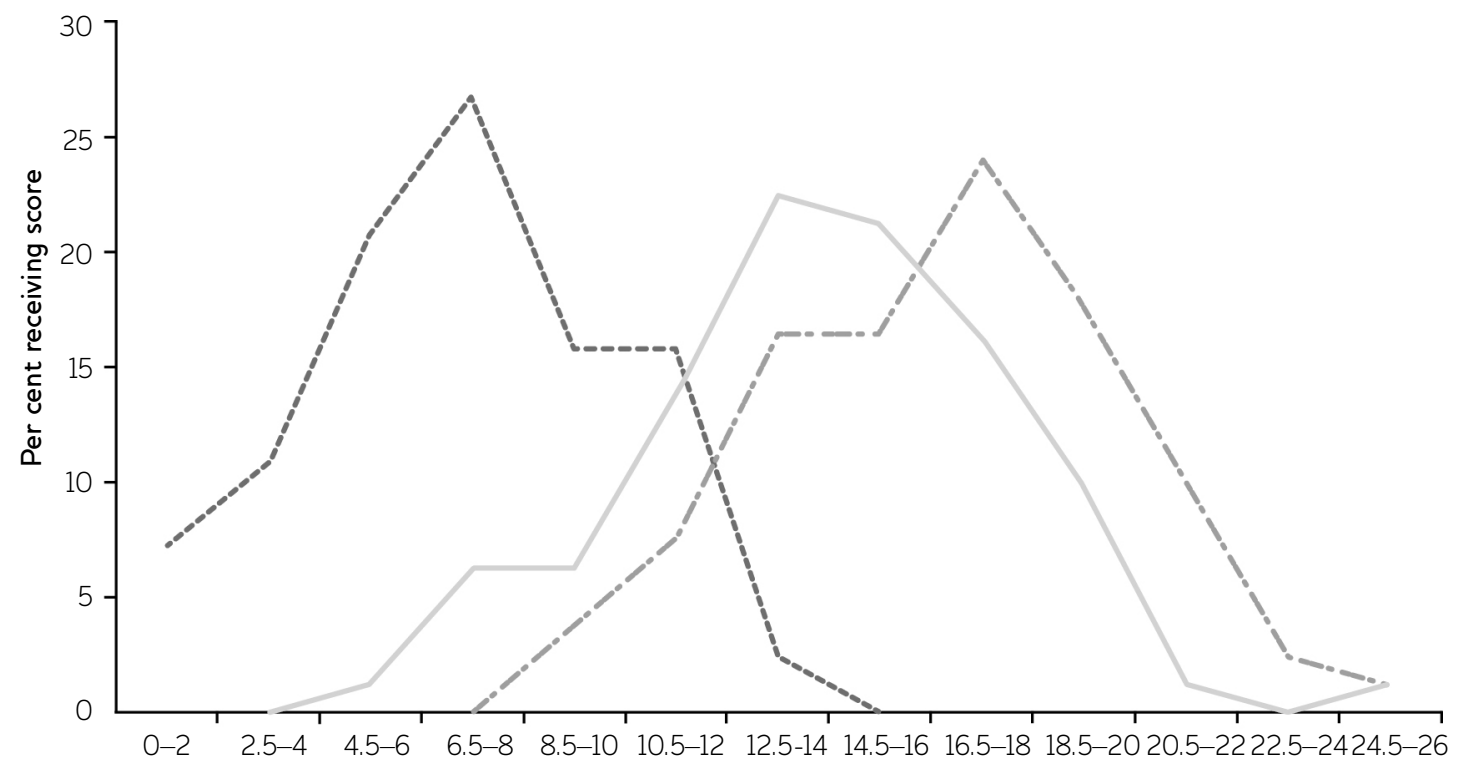

Score on Household Asset Index

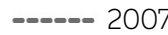
2012

Source Authors' own calculations based on existing data sets.

many children she has, how many children go to school, how many times per week they cook meat in the house and how many people live in the house. The score in 2012 had increased to 5.7 from 3.8 out of 13 in 2007, though this represented a slight slip from the 2009 score of 6.2 .

At the start of the programme in 2007, 81.7 per cent of participants could not read or write, 84.1 per cent had four or more children and slightly over half (51.2 per cent) lived in households of between four and six. In terms of school attendance, 42.7 per cent said that none of their children attended school and for 34.1 per cent a few attended; 91.5 per cent said that they occasionally cooked meat in the household. By 2012 the proportion of respondents who could not read or write had fallen to 60.5 per cent (though 27.2 per cent said they could only read), the proportion with four or more children increased slightly to 87.7 per cent and 48.1 per cent of respondents lived in households of size four to six and 30.9 per cent in households of seven to ten. However, the largest difference came in terms of the proportion of children who go to school - in 2012, 43.2 per cent of respondents said that all of their children attended school and 25.9 per cent said most did, compared to less than 10 per cent who said this was the case at baseline (see Figure 1 for an illustration of the trend across the three points in time). This is consistent with the comparison between the two groups in Boucan Carre, where 71.1 per cent of participants said that they sent all of their children to school (compared to 23.3 per cent amongst the non-beneficiaries) with no respondent saying that they didn't send any of their children to school (compared to 46.7 per cent amongst the non-beneficiaries).

Similarly, the proportion of respondents who said that they ate meat at least once a week had increased to 40.7 per cent in 2012, though this represents a decrease on the 52.4 per cent who ate meat at least once a week immediately after graduation. This all translates into 65 respondents (75.3 per cent) having a score on this sub-section that was better in 2012 than 2007, with five (6.2 per cent) having no change and 11 (13.6 per cent) registering a lower score.

\subsection{So, are participants better off now than at the start?}

One of the most important intended uses of the poverty scorecard was that it would be able to keep track of a participant's progress during the implementation of the CLM programme, and 


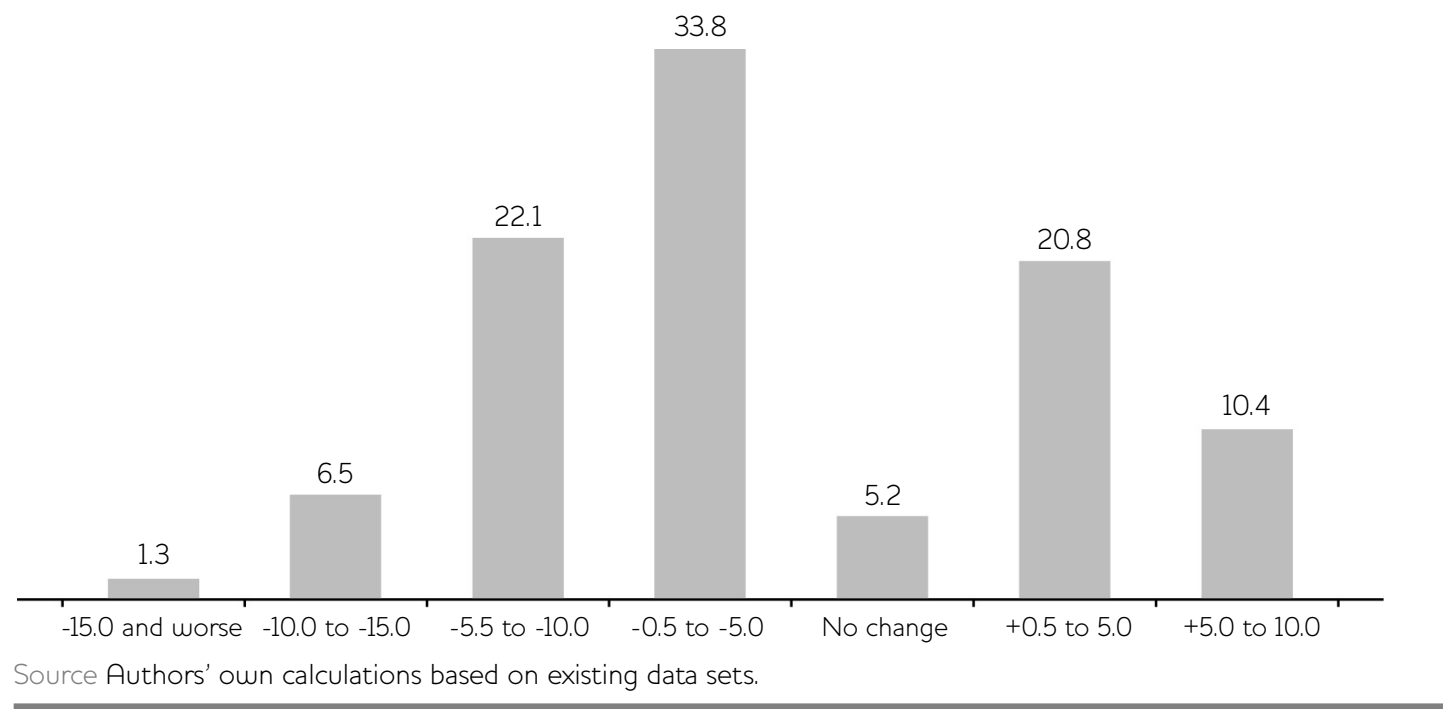

during an exercise such as this to see what happened to them subsequently. To ensure comparability across years, the answers to 16 of the questions which could reasonably be expected to show some variance over time ${ }^{9}$ were included in a revised poverty scorecard, giving a total maximum score of 42.5. Over time, the mean scores showed an increase from 7.2 at baseline to 16.6 at graduation, with a slight fall thereafter to 14.2 in 2012. The highest score recorded at any stage for any participant is 25.5, recorded in 2012, still a long way from the maximum of 42.5. This suggests that the 'average' level of household assets has increased considerably between the baseline and the survey carried out four years after graduation. In fact the small 'average' level of decline from six months after graduation to almost three and a half years later suggests that the benefits have been sustained.

Figure 2 shows the distributions of programme participants receiving specific scores for each year - at the baseline the spike, representing the most common ranges of scores, was between 6.5 and 8 (recorded by 26.8 per cent of beneficiaries). In 2009 this spike came between 16.5 and 18 points on the scorecard, in 2012 this had dropped back to between 12.5 and 14 (for 22.5 per cent of respondents).

It is also important to consider how many people have not improved or have in fact decreased their score between different points of time. Between the 2007 baseline and the survey carried out in 2012, 96.2 per cent of women included in the programme (equivalent to 77 participants) had a higher score; between baseline (2007) and graduation (2009), all except one (98.7 per cent) recorded a better score. However, it is between the graduation (2009) and four years later (2012) that a downward trend is observed, raising concern about households who slip back after graduation, underlining the importance of follow-up to ensure the benefits of the programme are sustainable for them.

The scale of this downward trend is also important; Figure 3 shows it is possible to divide respondents into three clear groups based on changes in their Kat Evalyasyon score between 2009 and 2012. The first comprises the 24 (31.2 per cent) beneficiaries who have continued on an upward trajectory after graduation; the second are the 30 (39.0 per cent) who have maintained the same score or have registered a small decline; the third are the 23 (29.9 per cent) beneficiaries who have recorded a sizable decline in their asset score after graduation. While the analysis shows that those who have managed to push on, are in general older and have a smaller number of children under five, understanding what happened to the group who have slipped back considerably needs more careful examination. 


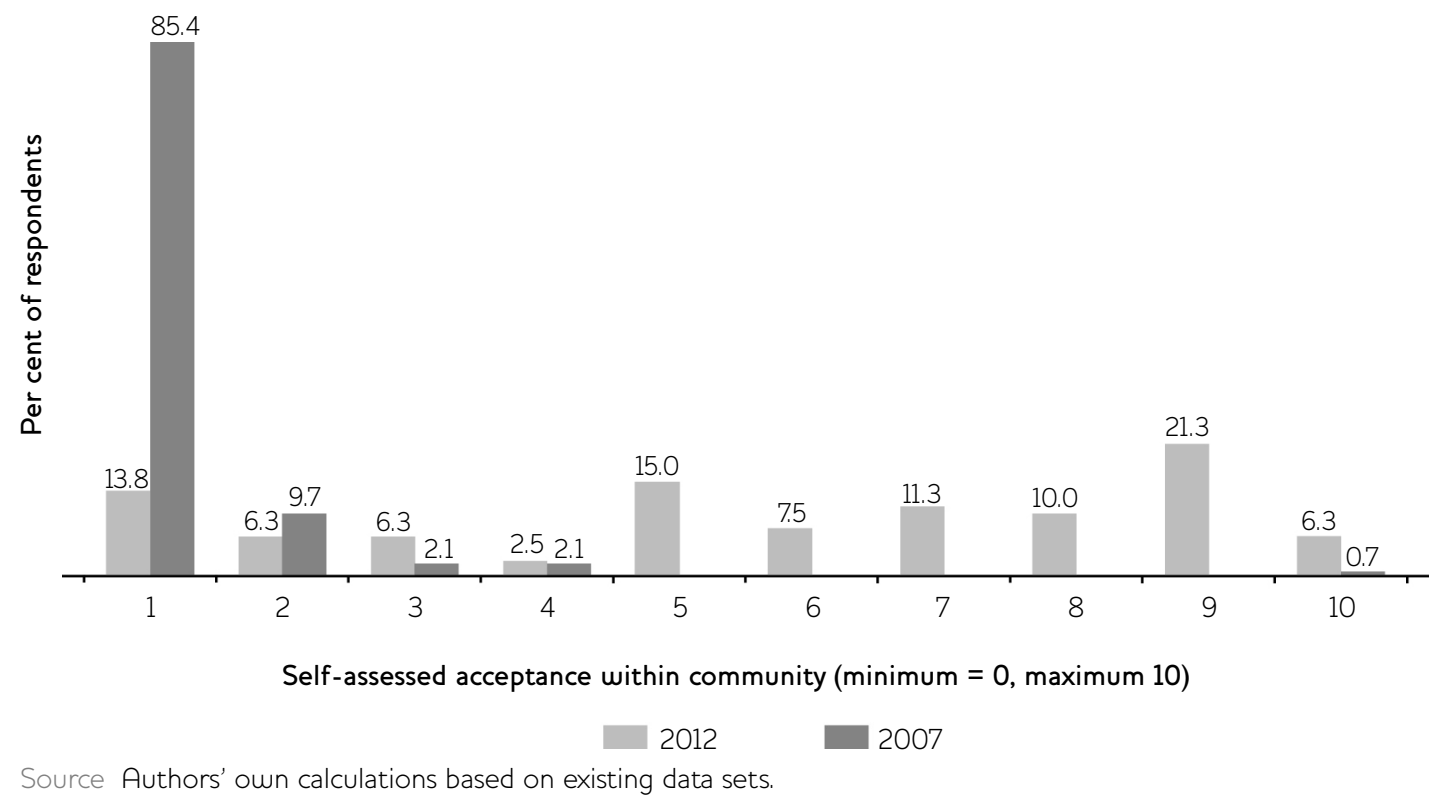

Within the overall score, different trends emerge across the various clusters of indicators, with the ones related to housing showing the largest improvement, likely a reflection of the fact that Fonkoze provided each household with cement, tin roofs and labour to renovate their existing homes, in addition to the actual programme. However, construction materials were provided before graduation so it does not explain the continued improvement in housing between graduation (2009) and 2012 for a large number of the participants. On the other hand, of particular concern are the changes in livestock holdings and income earned from these. As these were passed on as part of the asset transfer, they were to be the means by which the beneficiaries' continued progress out of poverty could be assured. However, the rather large proportion who reported having fewer animals in 2012 compared to the six months after graduation needs to be examined.

In addition to being asked about their assets in the Kat Evalyasyon, respondents were also asked about the level of respect they receive from the community. In both the 2007 and 2012 survey, they were asked to rank this on a score between one and ten. As Figure 4 shows, there has been a large improvement in the ranking of beneficiaries. In 2007, 85.4 per cent gave themselves a value of 1 , the lowest possible, while in 2012, only 13.8 per cent gave themselves this score, with 15 per cent placing themselves in the middle and 21.3 per cent giving themselves a score of nine. None of the respondents recorded that their position had worsened between the two points in time.

Interestingly there appears to be only a very weak correlation between the score on the Kat Evalyasyon and the respect score on the community scale both at baseline and in the 2012 survey, ${ }^{10}$ neither of which was significant. This would seem to reinforce that these are measuring two quite different concepts, and that such a programme impacts on many areas of the lives of extremely poor people. However, this is an area that requires considerably more research going forward, and would help to shift attention away from a focus on increasing the asset base of the household.

\section{Conclusions and lessons for learning}

The considerable proportion of households who have slipped back after 'graduation' is a cause for concern and at a programme level suggests the need for more concerted follow-up with beneficiaries in the post-graduation phase. It is also important to realise that graduation from a programme such as CLM does not mean that an extremely poor person will never slip back into poverty, underlining the need for consistent and 
universal national social protection policies which allow those who 'fall' to be caught by a safety net. Given the specific context of Haiti, it is also distinctly possible that even those who have slipped backwards are better off than their contemporaries are; the lack of a meaningful control group means this cannot be assessed, however.

When transferring a 'livelihood asset' to extremely poor people it is essential that support systems are in place to make sure they can utilise this. For instance, transferring animals as a livelihood asset, without ensuring there is a functioning veterinary service or that the beneficiaries have the capacity to manage the animals or access these services can lead to problems. Further, if there is a push for 'economic development' a comprehensive value chain analysis needs to be undertaken beforehand, and the appropriateness of the intervention should be checked.

In terms of being able to assess progress, over the six years of the programme, using a poverty scorecard based on ownership of selected household assets as a proxy for household income or expenditure is considerably easier for project staff to implement. The value of the tool is strengthened when ownership of the assets is observed to be closely correlated with poverty status based on the analysis of more complex household surveys. However, the appropriateness of some of the indicators included in the Kat Evalyasyon for monitoring purposes, as opposed to targeting, has to be questioned, and needs to be

\section{Notes}

1 Though not on the scale required in a country where 75 per cent of the population live below US $\$ 2$ per day and 49 per cent live in extreme poverty (below US $\$ 1$ per day) (Huda and Simanowitz 2009).

2 For more details on this approach, see Hashemi and de Montesquiou (2011).

3 See www.fonkoze.org/what-we-do/.

4 See http://graduation.cgap.org/pilots/chemenlavi-miyo/.

5 See for example, Huda and Simanowitz (2010: 201).

6 It is acknowledged that collecting data on only 82 beneficiaries from the first cohort does leave us with a small sample size; however, comparing the results for this group and the bigger group in 2007 and 2009 suggests that considered more carefully in the design of the monitoring and evaluation system. Further, the need to identify a scale that measures acceptability or empowerment in such a context is increasingly evident, while existing tools, such as the Household Dietary Diversity Score, should be used in a consistent manner to record data and track changes over time.

The ad hoc nature of much of the government's interventions in the area shows that there is a role for a programme such as CLM to play in informing government on what works (or does not). To date this 'advocacy' element of the work is one that has been neglected and opens the programme up somewhat to accusations that it too is another one of these ad hoc interventions disproportionately focused on the direct delivery to programme beneficiaries, erroneously informed by the common belief that no social protection systems exist in Haiti. This should be addressed if the programme is to avoid furthering the idea of the 'poor privileged people' (a term used by Lamaute-Brisson (2013) to describe those 'fortunate' enough to get included on an NGO programme like CLM). Initiatives such as the multipurpose community agent initiative undertaken by the government and the Ti Manman Cheri Programme, which targets families with young children living in extreme poverty for conditional cash transfer that ties the receipt of cash benefits to school enrolment, are ideal to share information on targeting and the success of the case worker.

there are no significant differences between the groups.

7 See http://data.worldbank.org/indicator/ NY.GNP.PGAP.PP.GD.

8 In a separate question respondents were asked to assess whether their incomes had increased, decreased or stayed the same in the past year, with 39 saying it had decreased, 32 saying it had stayed the same and eight saying it had increased in the 2012 survey. When this is correlated with the score on the $2012 \mathrm{Kat}$ Evalyasyon, it is apparent that there are very small differences between those who said their income had decreased (13.9) or stayed the same (13.8), but those who said their income had increased recorded a considerably higher score (17.3). 
9 House, roof, floor, own house, rooms, own land, toilet, bedding material, electricity, assets (TV/radio), land, use the land, livestock, read and write, children at school, cook meat.

\section{References}

Grameen Foundation (2014) Global Report on Poverty Measurement with the Progress out of Poverty Index (PPI), Washington DC, www.progressoutofpoverty.org/sites/default/ files/PPI\%20Global\%20Report\%202014.pdf (accessed 10 December 2014)

Hashemi, S.M. and de Montesquiou (2011) 'Reaching the Poorest: Lessons from the Graduation Model', Focus Note 69, Washington DC: CGAP

Huda, K. and Simanowitz, A. (2010) 'Chemin Levi Miyo - Final Evaluation (24 Months), On Behalf of Concern Worldwide Consultative Group to Assist the Poor (CGAP)', unpublished, http://graduation.cgap.org/library/chemenlavi-miyo-midterm-evaluation-3-jul-2008-hudak-simanowitz-a/ (accessed 16 December 2014)

Huda, K. and Simanowitz, A. (2009) 'A

Graduation Pathway for Haiti's Poorest: $10[\mathrm{r}=.05, \mathrm{n}=143 \mathrm{p}=.551][\mathrm{r}=.209, \mathrm{n}=78$, $\mathrm{p}=.066]$ respectively, where $\mathrm{R}=$ Pearson correlation, $\mathrm{N}=$ number in sample and $\mathrm{P}=$ probability.

Lessons Learnt from Fonkoze', Enterprise Development and Microfinance 20.2

Lamaute-Brisson, N. (2013) Social Protection Systems in Latin America and the Caribbean: Haiti, Santiago Chile, United Nations ECLAC, http://repositorio.cepal.org/bitstream/handle/ 11362/4075/S2013068_en.pdf?.sequence $=1$ (accessed 1 December 2014)

Samson, M. (2014) 'Session 1. Graduation Policies for the Poorest: Opportunities and Constraints: How does the Graduation Approach Fit into Social Protection Frameworks?', presentation made at Reaching the Poorest Global Learning Event 2014 CGAP-Ford Foundation Graduation Program, 19-21 February 2014, Paris, http://graduation.cgap.org/wp-content/ uploads/2014/02/Session-1_Samson_FINAL.pdf (accessed 8 December 2014) 